\title{
AVALIAÇÃO DOS EFEITOS DAS ATIVIDADES ANTRÓPICAS NA QUALIDADE DA ÁGUA DO RIO MARRECAS - FRANCISCO BELTRÃO/PR
}

\author{
EVALUATION OF THE EFFECTS OF ANTHROPOGENIC ACTIVITIES IN \\ WATER QUALITY RIVER MARRECAS - BELTRÃO FRANCISCO / PR
}

\author{
Karoline Begnini, Bruna Rafaella Fabris ${ }^{1}$ \\ Claudia Eugênia Castro Bravo, Ticiane Sauer Pokrywiecki, Ivane Benedetti Tonial ${ }^{2}$
}

\begin{abstract}
RESUMO
O presente estudo teve por objetivo verificar a interferência das atividades antrópicas na qualidade na água do Rio Marrecas, na zona urbana e rural, considerando o período de chuvas e de estiagem. Para a realização das análises, foram definidos quatro pontos de coleta previamente definidos e georreferenciados, sendo os pontos P1 e P2, localizados na região urbana, P3 e P4 zona rural. A avaliação da qualidade da água do rio marrecas foi realizada por meio de análises físico-químicas e microbiológicas. A análise dos resultados permitiu indicar que água do Rio Marrecas não apresenta grandes problemas de contaminação, e que os parâmetros analisados, atendem as especificações dos padrões de qualidade estabelecidos pela Resolução 357/2005 do CONAMA.
\end{abstract}

Palavras-chave: Zona Urbana, Zona Rural, Qualidade da Água.

\begin{abstract}
This study aimed to verify the influence of anthropogenic activities on water quality in the Rio Marrecas in urban and rural areas, considering the rainy season and drought. For the analyzes, we defined four collection points previously defined and georeferenced, the points P1 and P2, located in urban, P3 and P4 located in rural. The assessment of water quality of the river Marrecas was carried out by means of physico-chemical and microbiological. The results indicate that river water Marrecas no major contamination problems, and that the parameters analyzed, the specifications meet the quality standards established by Resolution 357/2005 CONAMA.
\end{abstract}

Key-words: Urban area, Rural Area, Water Quality.

\section{INTRODUÇÃO}

A água é um recurso de extrema necessidade para a sobrevivência dos seres vivos e desenvolvimento da humanidade. Está ligada a todos os ecossistemas do planeta

\footnotetext{
${ }^{1}$ Alunas de Graduação do Curso de Engenharia Ambiental da Universidade Tecnológica Federal do Paraná, Campus Francisco Beltrão - PR -Brasil.

${ }^{2}$ Professoras/Pesquisadoras da Universidade Tecnológica Federal do Paraná - Campus Francisco Beltrão -PR - Brasil. E-mail: ivane@utfpr.edu.br
} 
e sua qualidade e quantidade está cada vez mais vulneráveis pela falta de preservação e monitoramento ambiental (CRUZ et al., 2007).

Segundo Alves et al. (2008) “a qualidade da água é afetada tanto pelos fenômenos naturais quanto pela atuação do homem. As ações antrópicas decorrem do lançamento de esgotos domésticos e industriais em corpos hídricos, assim como, da aplicação de defensivos agrícolas no solo contribuindo para introdução de compostos orgânicos e/ou inorgânicos na água, afetando a sua qualidade.”

Uma das principais preocupações com a poluição das águas são as doenças por ela transmitidas. Os efeitos a curto e longo prazo sobre a saúde em seres humanos e animais dependem das características físicas e químicas dos poluentes e da exposição à água contaminada (JONNALAGADDA e MHERE, 2001).

A gestão de Recursos Hídricos definida na legislação brasileira contempla a preservação e bacias hidrográficas ou de rios, apenas indiretamente, na deliberação normativa do Conselho Nacional de Recursos Hídricos e na Lei das Águas (Lei 9.433/97) quando se refere a diversidade física e biótica (MACHADO, 2008). A referida Lei recomenda a bacia hidrográfica como sendo a unidade territorial para o Gerenciamento de Recursos Hídricos.

A bacia hidrográfica do Rio Marrecas localiza-se na região Sudoeste do estado do Paraná e apresenta uma área de aproximadamente $850 \mathrm{~km}^{2}$. Esta bacia nasce nos municípios de Flor da Serra do Sul e Marmeleiro, possui seu médio curso em Francisco Beltrão, onde concentra sua maior área, e desemboca nas cidades de Itapejara do Oeste e Verê (MACHADO, 2009).

Os impactos causados na Bacia hidrográfica do Rio Marrecas ocorreram através de intensas modificações feitas a partir de 1970, devido à mecanização agrícola e o desenvolvimento urbano. Assim, as áreas com floresta atlântica e mata de araucárias foram destruídas para a implantação de pastagens e plantações, bem como a construção das cidades (MACHADO, 2009).

As atividades antrópicas, relativas ao uso e a ocupação dos solos, relacionam-se diretamente com as alterações no comportamento hidrológico das bacias hidrográficas, particularmente no que se refere à origem e dinâmica do escoamento superficial, pois toda ação de planejamento que tenha por intuito o ordenamento territorial, focando atenuar ou eliminar os impactos ambientais derivados do uso e manejo do solo, deve ser 
precedida de diagnóstico e monitoramento prévio (CAMPANA, 2001; BIGUELINE, 2010).

Assim sendo, faz-se necessário um programa de diagnóstico e monitoramento de recursos hídricos, que forneça subsídios para avaliar as condições qualitativas e quantitativas do manancial e propiciar informações para a tomada de decisões, levando em consideração a questão espacial e temporal (MACEDO, 2007).

O Rio Marrecas é responsável pelo abastecimento do município de Francisco Beltrão e as atividades antrópicas, tais como, redução da mata ciliar, uso e manejo inadequado do solo e falta de saneamento básico podem afetam sua qualidade e compromete seus diversos usos. Assim sendo, o estudo da qualidade da água é fundamental para caracterizar as conseqüências das atividades poluidoras e com isso, definir e direcionar seus usos (CRUZ et al., 2007) bem como disponibilizar subsídios para o seu monitoramento.

Este trabalho teve como objetivo preliminar investigar os efeitos das atividades antrópicas na qualidade da água do rio Marrecas na zona urbana e rural no Município de Francisco Beltrão/PR em períodos de chuva e estiagem por meio de parâmetros físicoquímicos e microbiológicos, a fim de ofertar subsídios para tomada de decisões em ações de cunho mitigador, revitalizador /ou recuperador deste recurso hídrico.

\section{MATERIAIS E MÉTODOS}

\section{Localização da Área de Estudo}

O Município de Francisco Beltrão localiza-se na região central do Sudoeste do Paraná, cerca de $380 \mathrm{Km}$ (distância aérea) de Curitiba, capital do Estado. Possui área de $735 \mathrm{Km}^{2}$, cuja urbanização abrange aproximadamente $30 \mathrm{Km}^{2}$, com altitude de aproximadamente $500 \mathrm{~m}$ nas margens do Rio Marrecas e $948 \mathrm{~m}$ nas cabeceiras do arroio Jacutinga (IBGE, 2014). A Figura 1 mostra a localização geográfica do município no estado e no país. 


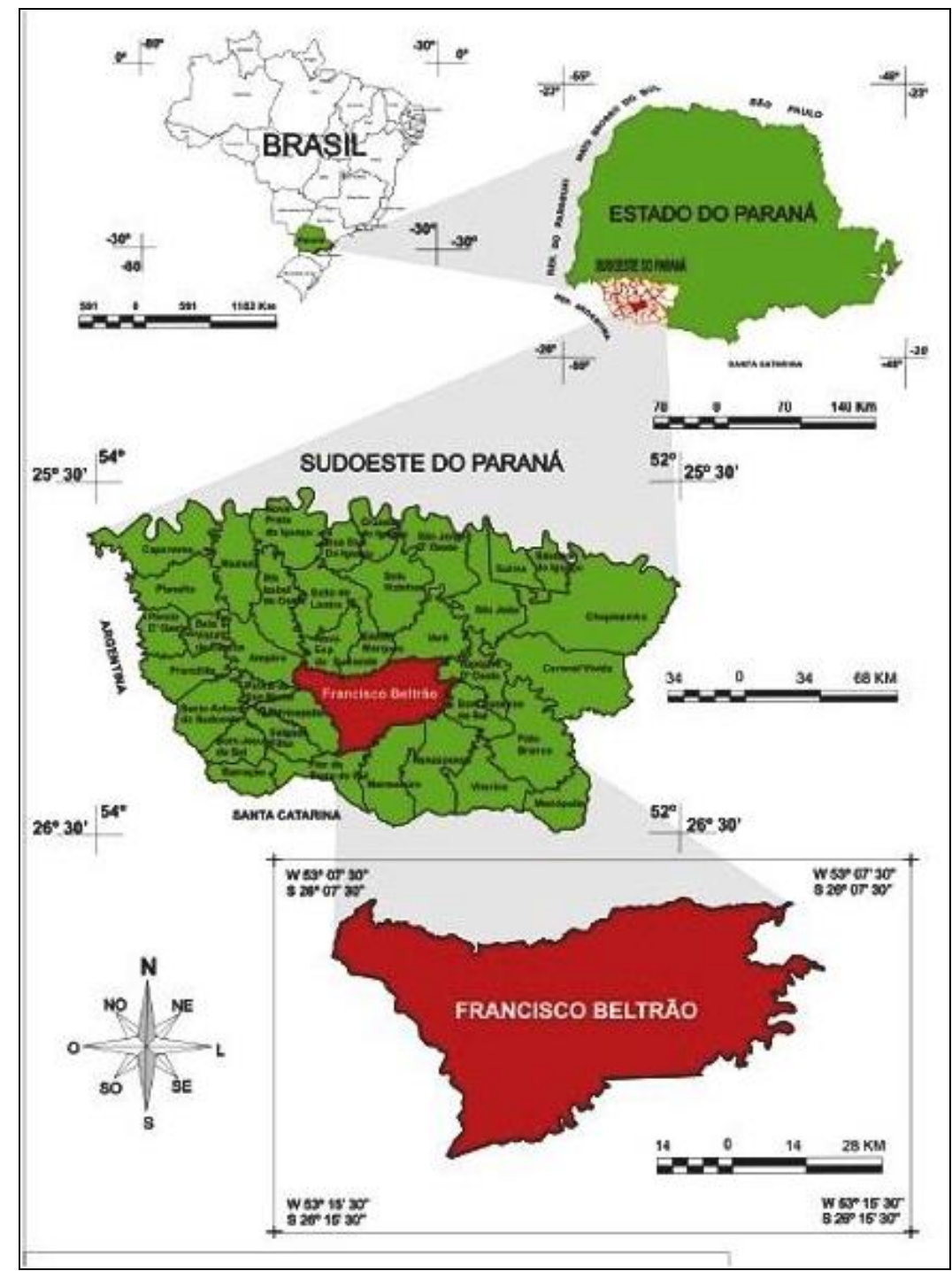

FIGURA 1: Localização geográfica do Município de Francisco Beltrão/PR (MONDARDO, 2009).

O Rio Marrecas é o principal formador da Bacia Hidrográfica do Rio Marrecas, nasce em Flor da Serra do Sul, passa por Marmeleiro e Francisco Beltrão, para desaguar no Rio Santana (MACHADO, 2009; BIGUELINI, 2013). Possui coordenadas geográficas, em latitude $25^{\circ} 54^{\prime} 48^{\prime}$ 'e $26^{\circ} 21^{\prime} 05^{\prime}$ ' Sul e longitudes $52^{\circ} 54^{\prime} 34^{\prime \prime}$ leste e 53¹7'03" Oeste (LUZ, 2006). É o rio responsável pelo fornecimento de água para abastecimento municipal e foi classificado pelo CONAMA 357/05 como sendo um rio de classe 2, podendo suas águas serem utilizadas para abastecimento doméstico após tratamento convencional (LUZ, 2011). A Figura 2 apresenta o mapa da bacia hidrográfica do Rio Marrecas. 


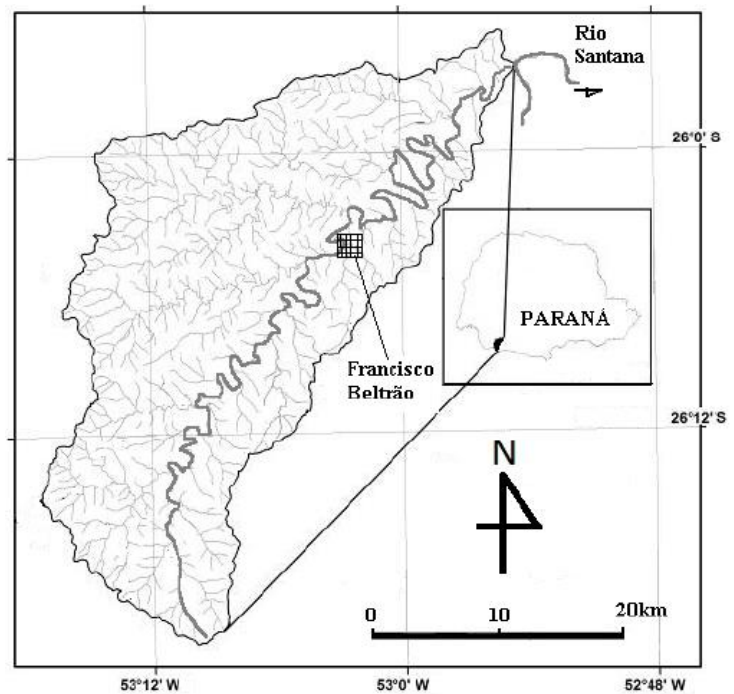

Figura 2: Bacia hidrográfica do Rio Marrecas (PAISANI et al., 2008 modificada por LUZ, 2010).

\section{Investigação da Qualidade da Água}

A investigação da qualidade da água do rio marrecas foi realizada por meio de análises físico-químicas e microbiológicas. As coletas foram realizadas considerando o período de estiagem e de chuvas.

Para a realização das análises, foram definidos quatro pontos de coleta previamente definidos e georreferenciados com o equipamento Global Positioning System - GPS, sendo dois pontos situados na zona urbana com predomínio de atividades comerciais e domiciliares e dois na zona rural, com predomínio de atividades agropecuárias. Na Figura 3 estão identificados os pontos de coleta com as seguintes coordenadas P1 (Zona Urbana: Latitude 264'21" e longitude 53³'25") ) P2 (Zona

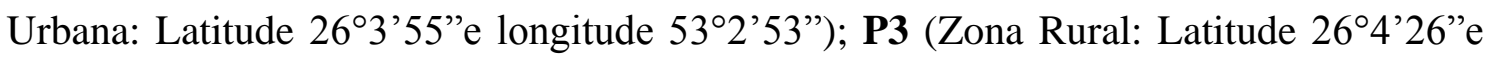

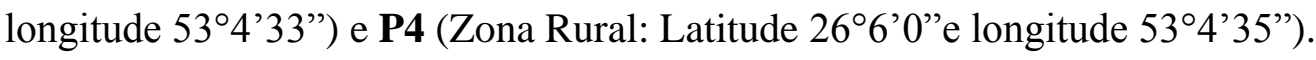




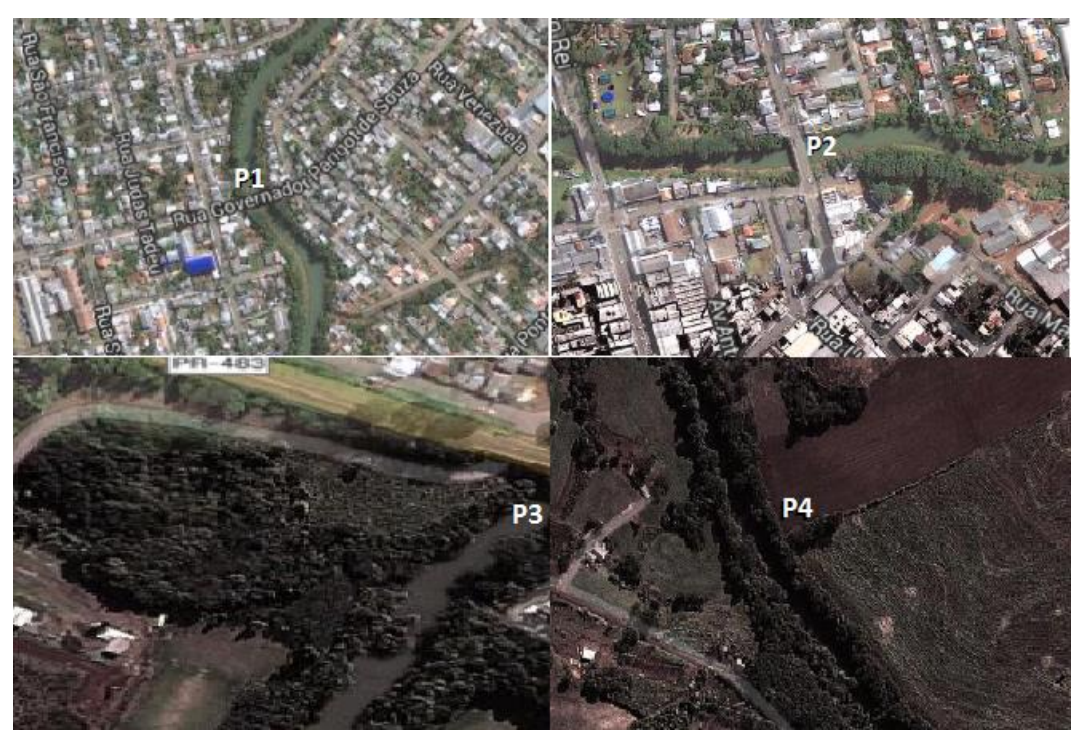

Figura 3. Localização dos pontos de coleta.

As amostras de água foram coletadas por amostragem simples, com auxílio de garrafa coletora de forma pontual no ponto central da seção do rio Marrecas. Para a coleta, transporte e preservação das amostras foram utilizadas metodologias descritas no “Standard Methods" (APHA, AWWA e WEF, 1998).

As determinações de $\mathrm{pH}$ e temperatura foram realizadas in loco e as demais análises foram realizadas em triplicata no laboratório de águas e efluentes da Universidade Tecnológica Federal do Paraná - Campus Francisco Beltrão conforme métodos descritos na Tabela 1.

Tabela 1. Métodos Analíticos utilizados nas determinações físico-químicas.

\begin{tabular}{ccc}
\hline Parâmetro & Método & Equipamentos \\
\hline Temperatura & Elétrométrico & MPA 210 P (TECNOPON) \\
$\mathrm{pH}$ & Elétrométrico & MPA 210 P (TECNOPON) \\
Cor & Nefelômetros & AquaColor (POLICONTROL) \\
Turbidez & Nefelômetros & AP 200 (POLICONTROL) \\
Condutividade & Eletrométrico & MCA 150 P (TECNOPON) \\
OD & Eletrométrico & HI 98186 (HANNA INSTRUMENTS) \\
DQO & Standard Methods & --- \\
Cloro R. Total & Nefelômetros & Clorimetro DPD (TECNOPON) \\
Sólidos Totais & Standard Methods & --- \\
\hline
\end{tabular}

--- Métodos do Standard Methods não possuem equipamentos efetivos de análise. 
A análise microbiológica foi realizada através da técnica de tubos múltiplos que determina o número mais provável (NMP) de coliformes por $\mathrm{mL}$ de amostra de água, segundo a Apha (1992). O número mais provável de coliformes foi obtido através da tabela de McGRADY, em que são dados os limites de confiança de 95\% para cada valor de NMP determinado.

Para o teste presuntivo de coliformes utilizou-se três tubos por diluição decimal $\left(10^{-1,} 10^{-2}, 10^{-3)}\right.$ com caldo Lauril Sulfato Triptose (LST). Após inoculação com $1 \mathrm{~mL}$ de cada diluição, foram incubados em estufa bacteriológica a $35^{\circ} \mathrm{C}$ por 48 horas. Passado o período de 48 horas, foram considerados positivos os tubos que apresentaram turbidez e produção de gás aprisionado. Para prova confirmativa (presença de coliformes totais) e indicativa (presença de coliformes termotolerantes) procedeu-se, com o auxílio de uma alça de platina, a transferência de cada cultura com resultado presuntivo positivo para tubos de ensaio contendo Caldo Verde Brilhante e bile 2\% (Caldo VBB) e tubos de ensaio com Caldo Escherichia coli (Caldo EC), sendo incubados por 48 horas a $35^{\circ} \mathrm{C} \mathrm{e}$ 24 horas a $44,5^{\circ} \mathrm{C}$, respectivamente.

Todas as análises foram realizadas, considerando-se o tempo de preservação para cada parâmetro e os resultados obtidos foram submetidos à análise de variância (ANOVA) a 5\% de probabilidade, pelo teste de Tukey, através do software Statistica, versão 7.0, (STATISTICA, 2007).

Os resultados foram avaliados por indicadores estabelecidos na Resolução Conama no 357 de 17/03/2005 que dispõe sobre a classificação dos corpos de água e as diretrizes ambientais pra o seu enquadramento, bem como estabelece as condições e padrões de lançamento de efluentes, e dá outras providências.

\section{RESULTADOS E DISCUSÃO}

Para investigar a qualidade da água e os efeitos da ação antrópica na bacia hidrográfica do Rio Marrecas nos pontos selecionados, utilizaram-se os resultados obtidos nas análises físico-químicas e microbiológicas da água em duas regiões distintas: urbana e rural, sob duas condições climáticas, estiagem e chuva.

Nas Tabelas 2 e 3, estão apresentados os resultados dos parâmetros físicoquímicos analisados durante o período chuvoso e de estiagem, respectivamente. Os 
resultados são apresentados pela média de três replicatas acompanhadas do desvio padrão e tratamento estatístico pela análise de variância (ANOVA) e Teste de Tukey.

Tabela 2. Resultado dos parâmetros Físico-químicos avaliados no período chuvoso.

\begin{tabular}{|c|c|c|c|c|c|}
\hline \multirow{2}{*}{ Parâmetros } & \multicolumn{2}{|c|}{ Zona Urbana } & \multicolumn{2}{|c|}{ Zona Rural } & \multirow{2}{*}{ Res.357/05 } \\
\hline & P 1 & P 2 & P 3 & P 4 & \\
\hline $\mathrm{pH}$ & 6,68 & 6,90 & 6,85 & 7,02 & 6,0 a 9,0 \\
\hline $\mathrm{T} /{ }^{\circ} \mathrm{C}$ & 19,70 & 19,80 & 20,00 & 20,00 & $<40$ \\
\hline COND. $(\mu \mathrm{S} / \mathrm{cm})$ & $52,53 \pm 0,03^{\mathrm{b}}$ & $71,82 \pm 0,19^{\mathrm{d}}$ & $47,88 \pm 0,14^{\mathrm{a}}$ & $53,62 \pm 0,03^{\mathrm{c}}$ & $\leq 100$ \\
\hline $\mathrm{OD}\left(\mathrm{mg} / \mathrm{L} \mathrm{O}_{2}\right)$ & $4,45 \pm 0,04^{\mathrm{ab}}$ & $4,68 \pm 0,18^{b}$ & $3,56 \pm 0,06^{\mathrm{a}}$ & $4,10 \pm 0,67^{\mathrm{ab}}$ & $\geq 5$ \\
\hline TURB.(UNT) & $15,23 \pm 0,15^{\mathrm{a}}$ & $14,87 \pm 0,25^{\mathrm{a}}$ & $15,17 \pm 0,15^{\mathrm{a}}$ & $19,33 \pm 0,21^{b}$ & $\leq 100$ \\
\hline COR(Pt.Co/L) & $55,55 \pm 0,78^{\mathrm{a}}$ & $56,35 \pm 0,78^{\mathrm{a}}$ & $61,20 \pm 0,14^{\mathrm{a}}$ & $64,25 \pm 0,64^{\mathrm{a}}$ & $\leq 75$ \\
\hline $\mathrm{ClRT}(\mathrm{mg} / \mathrm{L})$ & $0,18 \pm 0,01^{\mathrm{a}}$ & $0,12 \pm 0,02^{\mathrm{a}}$ & $0,17 \pm 0,01^{\mathrm{a}}$ & $0,17 \pm 0,01^{\mathrm{a}}$ & 0,01 \\
\hline $\mathrm{ST}(\mathrm{mg} / \mathrm{L})$ & INS & INS & INS & INS & 500 \\
\hline $\mathrm{DQO}\left(\mathrm{mg} / \mathrm{LO}_{2}\right)$ & $27,23 \pm 0,01^{b}$ & $24,64 \pm 0,01^{\mathrm{a}}$ & $23,89 \pm 0,01^{\mathrm{a}}$ & $25,07 \pm 0,01^{\mathrm{a}}$ & $\mathrm{NC}$ \\
\hline
\end{tabular}

COND: Condutividade; DP: Desvio padrão; OD: Oxigênio dissolvido; TURB: Turbidez; CIRT: Cloro Residual Total; ST: Sólidos Totais; DQO: Demanda Química de Oxigênio; INS: Valores considerados Insignificantes; UNT: Unidade Nefelométrica de Turbidez, NC: Não Contempla. Os resultados são médias em triplicatas com as respectivas estimativas do desvio padrão. Valores na mesma linha seguidos de letras iguais não diferem entre si ( $p>0,05)$. [Análise de variância - ANOVA e Teste de Tukey].

Tabela 3. Resultado dos parâmetros Físico-químicos avaliados no período de estiagem.

\begin{tabular}{|c|c|c|c|c|c|}
\hline \multirow{2}{*}{ Parâmetros } & \multicolumn{2}{|c|}{ Zona Urbana } & \multicolumn{2}{|c|}{ Zona Rural } & \multirow{2}{*}{ Res.357/05 } \\
\hline & $\overline{\mathbf{P} 1}$ & P 2 & P 3 & P 4 & \\
\hline $\mathrm{pH}$ & 7,06 & 7,26 & 7,36 & 7,40 & 6,0 a 9,0 \\
\hline $\mathrm{T} /{ }^{\circ} \mathrm{C}$ & 22,10 & 22,40 & 22,50 & 22,40 & - \\
\hline COND. $(\mu \mathrm{S} / \mathrm{cm})$ & $58,26 \pm 0,01^{\mathrm{c}}$ & $55,55 \pm 0,03^{b}$ & $51,77 \pm 0,02^{\mathrm{a}}$ & $51,85 \pm 0,01^{\mathrm{a}}$ & Até 100 \\
\hline $\mathrm{OD}\left(\mathrm{mg} / \mathrm{L} \mathrm{O}_{2}\right)$ & $7,19 \pm 0,43^{b}$ & $6,44 \pm 0,39^{\mathrm{a}}$ & $6,50 \pm 0,42^{\mathrm{a}}$ & $6,02 \pm 0,01^{\mathrm{a}}$ & $\geq 5$ \\
\hline TURB.(UNT) & $6,96 \pm 0,01^{\mathrm{b}}$ & $5,71 \pm 0,01^{\mathrm{a}}$ & $8,16 \pm 0,01^{\mathrm{c}}$ & $5,12 \pm 0,03^{\mathrm{a}}$ & $\leq 100$ \\
\hline COR(Pt.Co/L) & $35,65 \pm 0,07^{\mathrm{c}}$ & $32,40 \pm 0,01^{\mathrm{b}}$ & $33,43 \pm 1,05^{\mathrm{b}}$ & $31,00 \pm 0,56^{\mathrm{a}}$ & $\leq 75$ \\
\hline $\mathrm{ClRT}(\mathrm{mg} / \mathrm{L})$ & $0,21 \pm 0,01^{\mathrm{a}}$ & $0,13 \pm 0,02^{\mathrm{a}}$ & $0,27 \pm 0,01^{\mathrm{a}}$ & $0,17 \pm 0,02^{\mathrm{a}}$ & 0,01 \\
\hline $\mathrm{ST}(\mathrm{mg} / \mathrm{L})$ & INS & INS & INS & INS & 500 \\
\hline $\mathrm{DQO}\left(\mathrm{mg} / \mathrm{LO}_{2}\right)$ & $1,30 \pm 0,01^{\mathrm{a}}$ & $3,89 \pm 0,01^{\mathrm{c}}$ & $2,5 \pm 0,01^{\mathrm{b}}$ & $3,9 \pm 0,01^{\mathrm{c}}$ & $\mathrm{NC}$ \\
\hline
\end{tabular}

COND: Condutividade; DP: Desvio padrão; OD: Oxigênio dissolvido; TURB: Turbidez; CIRT: Cloro Residual Total; ST: Sólidos Totais; DQO: Demanda Química de Oxigênio; INS: Valores considerados Insignificantes; UNT: Unidade Nefelométrica de Turbidez, NC: Não Contempla. Os resultados são médias em triplicatas com as respectivas estimativas do desvio padrão. Valores na mesma linha seguidos de letras iguais não diferem entre si (p>0,05). [Análise de variância - ANOVA e Teste de Tukey]. 
Observa-se nas Tabelas acima que os resultados dos parâmetros físico-químicos: $\mathrm{pH}$, condutividade elétrica, sólidos totais, turbidez e cor, apresentam-se dentro dos padrões estabelecidos pela Resolução do CONAMA 357/2005, para rios de classe II, no qual se enquadra o Rio Marrecas.

Os valores de $\mathrm{pH}$ não apresentaram variações elevadas entre os pontos selecionados para as coletas e entre as coletas realizadas em períodos de chuva e estiagem apresentando valores dentro dos limites estabelecidos pela Resolução Conama $n^{\text {o } 357 / 2005 ~-~(6,0 ~ a ~ 9,0 ~ R i o ~ c l a s s e ~ I I) . ~ P a r a ~ J o n n a l a g a d d a ~ e ~ M h e r e ~(2001), ~ s i s t e m a s ~}$ aquáticos com fluxos sem poluição normalmente mostram uma faixa de $\mathrm{pH}$ quase neutra ou ligeiramente alcalina, como se mostrou as águas do Rio Marrecas para este parâmetro.

A temperatura da água variou de $19,70^{\circ} \mathrm{C}$ a $20,00^{\circ} \mathrm{C}$ no período chuvoso, e $22,10^{\circ} \mathrm{C}$ a $22,50^{\circ} \mathrm{C}$ no período de estiagem. Não existem valores definidos para a temperatura na legislação (357/05), no entanto este parâmetro pode influenciar os demais, como o oxigênio dissolvido, pois quanto menor a temperatura, maior a oxigenação da água (STROHSCHOEN et al., 2009).

A condutividade indica a quantidade de sais existentes na coluna d'água, sendo uma medida indireta da concentração de poluentes. As medidas de condutividade registraram valores entre 47,88 a $71,82 \mu \mathrm{S} / \mathrm{cm}$ para o período chuvoso, e entre 51,77 a $58,26 \mu \mathrm{S} / \mathrm{cm}$ para o período estiagem. Em geral, níveis superiores a $100 \mu \mathrm{S} / \mathrm{cm}$ indicam ambientes impactados (CETESB, 2012). Os valores encontrados para parâmetro neste estudo indicam que tanto no período de estiagem quanto no período de chuvas o recurso hídrico avaliado não se encontra impactado. Porém para o período de secas os valores encontrados são relativamente baixos quando comparados aos trabalhos realizados por Carvalho e Siqueira (2011), no Rio Meia Ponte em Goiânia-Goiás, cujo valores de condutividade variaram entre 98,30 e 190,00 $\mu \mathrm{S} / \mathrm{cm}$; o mesmo foi observado por Borsatto et al. (2010), onde a condutividade variou entre 45,03 a 262,00 $\mu \mathrm{S} / \mathrm{cm}$.

A concentração de oxigênio dissolvido (OD) variou de 3,56 a 4,68 mg/L de $\mathrm{O}_{2}$ para o período chuvoso, estando fora do limite mínimo estabelecidos pela Resolução Conama $\mathrm{n}^{\circ} 357 / 2005$ para corpos de água doce de Classe II (não inferior a $5 \mathrm{mg} / \mathrm{L}$ de $\mathrm{O}_{2}$ ). Já a concentração OD para o período de estiagem, variou de 6,02 a 7,19 $\mathrm{mg} \mathrm{L}^{-1}$ de $\mathrm{O}_{2}$ enquadrando-se nos limites estabelecidos, indicando que os períodos de variação de 
precipitação influenciaram na qualidade das águas. Os valores de OD encontrados neste estudo situam-se entre os valores encontrados por Macedo (2007) que apresentou valores que variaram de 1,3 a $8,7 \mathrm{mg} / \mathrm{L}$ de $\mathrm{O}_{2}$ em monitoramento da sub-bacia do Ribeirão das Cruzes em Araraquara/SP.

O oxigênio dissolvido (OD) é um excelente indicativo da qualidade da água e quanto maior sua concentração melhor é a qualidade da mesma. Esse parâmetro é utilizado para avaliar o efeito de despejos oxidáveis no recurso hídrico e indicar as condições de vida na água (MACÊDO, 2005).

A ocorrência de turbidez nas águas esta associada à presença de partículas de rocha, argila e silte, ou até mesmo microrganismos (VASCO et al., 2010). A variável turbidez teve seus valores entre 14,87 e 19,33 Unidade nefelométrica de turbidez (UNT) no período chuvoso, e valores com redução de aproximadamente metade no período de estiagem (5,12 a 8,16 UNT), diferença essa que se justifica pelo fato de que durante a estação chuvosa, ocorre a erosão das margens dos rios, pelo mau uso do solo, resultando no fenômeno da turbidez (CETESB, 2012).

Valores de turbidez observados por Donadio et al. (2005) em trabalho de avaliação da qualidade da água na bacia hidrográfica do Córrego Rico, indicam que os níveis variam de 2,40 a 28 UNT. Os valores de turbidez no presente estudo encontramse entre os valores apresentados pelos autores citados. A turbidez, segundo o mesmo autor é uma das variáveis que mais indica a qualidade das águas, e que a mesma pode ser alterada pela ausência de vegetação ciliar.

O parâmetro cor não apresentou diferença estatística entre seus valores no período chuvoso, no entanto, no período de estiagem foi observado que os pontos P2 e P3 são iguais estatisticamente, enquanto os pontos P1 e P4 são diferentes para o nível de $5 \%$ de significância.

A concentração da cor nos pontos estudados variou na faixa de 55,55 a 64,25 Pt.Co/L para o período chuvoso e de 31,00 a 35,65 Pt.Co/L para o período de estiagem, valores estes inferiores aos encontrados por Santos et al. (2007), em estudos na bacia hidrográfica do Córrego Romão dos Reis, Viçosa-MG, onde os valores de cor variaram entre 20 e 100 Pt.Co/L. 
Normalmente, a cor na água ocorre pela presença de ácidos húmicos e tanino, originados da decomposição de vegetais, bem como também de origem antrópica, através do lançamento de resíduos industriais e domiciliares (ALVES et al., 2008).

A concentração de sólidos totais nas amostras coletadas apresenta valores insignificantes, nos dois períodos analisados, estando de acordo com a Resolução Conama 357/05, para Águas doces (Classe 2), que estabelece um valor de $500 \mathrm{mg} / \mathrm{L}$. O parâmetro sólidos totais constitui a soma dos teores de todos os constituintes minerais presentes na água correlacionando-se diretamente com a condutividade (NERES et al., 2011).

As concentrações da demanda química de oxigênio (DQO) obtidas para o período chuvoso variaram de 23,89 a $27,23 \mathrm{mg} / \mathrm{L} \mathrm{O}_{2}$ e para o período de estiagem de 1,30 a 3,9 mg/L $\mathrm{O}_{2}$, não existem valores padrões estabelecidos pela legislação para este parâmetro. No entanto, a demanda química de oxigênio consiste em uma avaliação quantitativa direta do potencial de matéria redutora de uma amostra, através de um processo de oxidação química (BUENO, 2011).

Em trabalho realizado por Maciel e Macedo (2007), na bacia hidrográfica do Rio Ribeirão das Cruzes, em Araraquara-SP, os valores de DQO obtidos também variaram em valores próximos de 1,30 a 27,23 mg/L O $\mathrm{O}_{2}$, sendo estes, semelhantes aos valores encontrados neste estudo. Segundo os mesmos autores, as variações nas concentrações de DQO podem ter ocorrido pelo uso inadequado do solo e pelo lançamento de esgotos sem devido tratamento.

Indicadores microbiológicos são frequentemente utilizados para verificar a contaminação de corpos d'água por microorganismos responsáveis pela transmissão de doenças de veiculação hídrica (GARCIA e ALVES, 2006).

Tipicamente são utilizados organismos que são encontrados em elevadas concentrações nas fezes humanas (VASCONCELLOS et al., 2006). Segundo Shibata et al. (2004) geralmente utiliza-se, como indicadores coliformes totais, coliformes termotolerantes, dentre outros.

Na Tabela 5, estão apresentados os resultados das análises microbiológicas através do número mais provável (NMP) de coliformes por $\mathrm{mL}$ de amostra de água para as coletas realizadas no período de chuvas e de estiagem. 
Tabela 5. Número mais provável de coliformes para o limite de $95 \%$ de confiança encontrados nos respectivos pontos de coleta.

\begin{tabular}{|c|c|c|c|}
\hline $\begin{array}{c}\text { Zonas de } \\
\text { Amostragem }\end{array}$ & Pontos de Coleta & $\begin{array}{c}\text { CT } \\
\left(\mathbf{N M P ~} \mathbf{m L}^{-1}\right)\end{array}$ & $\begin{array}{c}\text { CTT } \\
\left(\mathbf{N M P ~} \mathbf{~ m L}^{-1}\right)\end{array}$ \\
\hline \multirow{2}{*}{ Zona Urbana } & $\mathrm{P} 1$ & $2,0 \times 10^{1}$ & $1,1 \times 10^{1}$ \\
\hline & $\mathrm{P} 2$ & $2,1 \times 10^{2}$ & $2,8 \times 10^{1}$ \\
\hline \multirow{2}{*}{ Zona Rural } & P3 & $1,5 \times 10^{1}$ & $1,5 \times 10^{1}$ \\
\hline & P4 & $0,9 \times 10^{1}$ & $<3$ \\
\hline
\end{tabular}

CT: Coliformes Totais; CTT: Coliformes Termotolerantes; NMP: Número mais Provável.

Em todos os pontos de coleta investigados foram encontrados coliformes totais e coliformes termotolerantes. Os maiores índices de poluição por este microorganismos ocorreram no ponto $\mathrm{P} 2$, localizados na área urbana, onde possivelmente há despejos de efluentes domésticos e industriais, que podem ter contribuído para a poluição do rio. Efluentes domésticos, industriais ou de origem animal podem causar alterações nos fatores bióticos e abióticos de ecossistemas naturais (ALMEIDA et al., 2004), podendo comprometer a qualidade da água, da vida aquática e da saúde da população. Além das análises microbiológicas, sugere-se para um próximo estudo a execução de testes ecotoxicológicos, os quais auxiliam a avaliação e monitoramento da qualidade da água (MAGALHÃES e FERRÃO FILHO, 2008).

Pelo fato do Rio Marrecas ser amplo e extenso sugere-se uma avaliação mais ampla, como maior número de pontos de coleta a fim de ter o representativo geral da bacia possibilitando a identificação dos possíveis pontos críticos, e assim poder desenvolver neste recurso hídrico técnicas de recuperação e revitalização.

A Lei das Águas preconiza bacia hidrográfica no contexto brasileiro dos recursos hídricos como unidade básica de planejamento (BRASIL, 1997). Neste sentido a criação de um Comitê de bacias para a Bacia Hidrográfica do Rio Marrecas seria uma excelente alternativa para gerar conhecimentos dos diversos tipos de ocupação ao longo da bacia, podendo ainda ser empregadas na orientação para elaboração de políticas publicas voltadas a preservação, conservação ambiental e também no conhecimento das potencialidades para fins de melhor uso e ocupação atual e futura (ESCADA e ALVES, 2001). 


\section{CONSIDERAÇÕES FINAIS}

Através da análise dos resultados pode-se concluir que os parâmetros físicoquímicos analisados, atenderam as especificações dos padrões de qualidade estabelecidos pela Resolução 357/2005 do CONAMA, para rios de classe II.

Microbiologicamente pode-se constatar que a ação antrópica está degradando a qualidade da água do Rio Marrecas, principalmente na região urbana, onde se constatou maior presença de coliformes. Sugere-se para um próximo estudo também a aplicação de Biotestes, que poderão confirmar esta contaminação.

Sugere-se também, um mapeamento ao longo da bacia para a localização e identificação de possíveis fontes poluentes bem como tomada de medidas mitigadoras e de recuperação ambiental nos pontos mais vulneráveis. A criação de um comitê de Bacia e a construção de políticas públicas poderia contribuir e auxiliar no monitoramento em ambas as regiões (urbana e rural) do Rio Marrecas preservando desta forma a qualidade da água, da vida aquática e saúde da população.

\section{AGRADECIMENTOS}

O presente estudo foi realizado com apoio financeiro e concessão de bolsa da UTFPR em apoio à Educação, Pesquisa e Desenvolvimento Científico e Tecnológico.

\section{REFERÊNCIAS}

ALMEIDA, R. M. A. A.; HUSSAR, G. J.; PERES, M. R.; FERRIANI, A. L. J. Qualidade Microbiológica do Córrego "Ribeirão dos Porcos" no Município de Espírito Santo do Pinhal -SP. Engenharia Ambiental, Espírito Santo do Pinhal, 2004.

ALVES, E. C.; SILVA, C. F.; COSSICH, E. S.; TAVARES, C. R. G.; SOUZA, E. E. F.; CARNIEL, A. Avaliação da Qualidade da Água da Bacia do Rio Pirapó-Maringá, Estado do Paraná, Por Meio de Parâmetros Físicos, Químicos e Microbiológicos. Acta Science and Technology, Maringá, v.30, n.1, 2008.

AMERICAN PUBLIC HEALTH ASSOCIATION - APHA, AWWA, WEF. Standard methods for the examination of water and wastewater. 20 ed. Washington: American Public Health Association, 1998. 
AMERICAN PUBLIC HEALTH ASSOCIATION - APHA, AWWA, WEF. Standard methods for the examination of water and wastewater. 18 ed. Washington: American Public Health Association, 1992.

BIGUELINI, C.P. Contextualização da paisagem em uma avaliação de indicadores ambientais de degradação hídrica. Perspectiva Geográfica, 130-152p. 2010.

BIGUELINI, C.P. Qualidade da água e poder de depuração do Rio marrecas em seu médio e baixo curso. Dissertação (Mestre em Geografia), Universidade Estadual do Oeste do Paraná, 2013, 175p. UNIOESTE - Francisco Beltrão, 2013.

BORSATTO, J. C. L.; BORSATTO, M. V.; ORLANDO, J. F. F.; SILVA, M. F. de.; SILVA, D. G. K. C. Análise da Qualidade da Água nos Rios Tocantins e Cacau no Trecho da Construção da Ponte da Amizade. Revista de Engenharia Ambiental, 2010.

BRASIL, LEI N 9433, DE 08 DE JANEIRO DE 1997. Institui a Política Nacional de Recursos Hídricos, cria o Sistema Nacional de Gerenciamento de Recursos Hídricos, regulamenta o inciso XIX do art. 21 da Constituição Federal, e altera o art. $1^{\circ}$ da Lei $n^{\circ}$ 8.001, de 13 de março de 1990, que modificou a Lei $\mathrm{n}^{\circ}$ 7.990, de 28 de dezembro de 1989. Brasília, 1997.

BUENO, R. F. Comparação Entre o Método Colorimétrico e Titulométrico na Determinação da DQO. Revista TAE, $2^{\circ}$ ed., 2011.

CAMPANA, N. A. Monitoramento do uso do solo. Apud PAIVA, J. B. D. de; PAIVA, E. M. C. de (org). Hidrologia aplicada à gestão de pequenas bacias hidrográficas. Porto Alegre: ABRH, p.507-529, 2001.

CARVAlHO, G. L.; SIQUEIRA, E. Q. Qualidade da Água do Rio Meia Ponte no Perímetro Urbano do Município de Goiânia-Goiás. Revista eletrônica de engenharia civil, v.1, 2011.

CETESB. Companhia de Tecnologia de Saneamento Ambiental. Qualidade das Águas Interiores no Estado de São Paulo. Disponível em: <http://www.cetesb.sp.gov.br/userfiles/file/agua/aguas-superficiais/variaveis.pdf>.

Acessado em: 09 de junho de 2012.

CONSELHO NACIONAL DO MEIO AMBIENTE - CONAMA. 2005. Resolução Conama $\quad \mathrm{n}^{\circ} \quad 357 . \quad$ Disponível em: <http://www.mma.gov.br/port/conama/res/res05/res35705.pdf> Acessado em: 14 mar. 2012.

CRUZ, P.; BARROS, A.; BRITO, J.; CARVALHO, L. Análise Quali-quantitativa da Água do Rio Parnaíba no Trecho dos Lavadores de Carro na Avenida Maranhão em Teresina/PI. II CONNEPI 2007, João Pessoa, 2007. 
CRUZ, P.; REIS, L.; BARROS, A.; NEVES, J.; CÂMARA, F. Estudo Comparativo da Qualidade Físico-química da Água no Período Chuvoso e Seco na Confluência dos Rios Poti e Parnaíba em Teresina/PI. II CONNEPI 2007, João Pessoa, 2007.

DONADIO, N. M. M.; GALBIATTI, J. A.; PAUlA, R. C. de. Qualidade da Água de Nascentes com Diferentes Usos do Solo na Bacia Hidrográfica do Córrego Rico, São Paulo, Brasil. Engenharia Agrícola, Jaboticabal, v.25, 2005.

ESCADA, M. I. S.; ALVES, D. S. Indicadores para a Compartimentação da Paisagem em Unidades de Ocupação em uma Região de Fronteira Agrícola em Rondônia. Apud Simpósio Brasileiro de Sensoriamento Remoto, 11., 2003, Belo Horizonte. Anais... São José dos campos: INPE, p. 1099-1106. 2001.

GARCIA, C. A. B.; ALVES, J. P. H. Qualidade da água. Relatório de Pesquisa LQA/UFS. São Cristóvão, 2006. In: Diagnóstico e avaliação da sub-bacia hidrográfica do rio Poxim. Relatório de Pesquisa. UFS/FAPESE. São Cristóvão, 2006.

IBGE - Instituto Brasileiro de Geografia e Estatística. Município de Francisco Beltrão, Paraná. Disponível em: http://www.ibge.gov.br/home/ Acesso em 02 de maio de 2014.

JONNALAGADDA, S. B.; MHERE, G. WATER QUALITY OF THE ODZI RIVER IN THE EASTERN HIGHLANDS OF ZIMBABWE. Elsevier Science Ltd.,GrãBretanha, 2001.

LUZ, C. E. Diagnóstico físico-químico e microbiológico das águas do rio Marrecas Francisco Beltrão/PR. Francisco Beltrão, 2006. 120p. Monografia (Graduação em Geografia). UNIOESTE - Francisco Beltrão, 2006.

LUZ, C. E. Tendências granulométricas dos sedimentos de fundo no Rio Marrecas, região Sudoeste do Paraná. Francisco Beltrão, 2011. 78p. Dissertação (Mestrado em Geografia). UNIOESTE - Francisco Beltrão, 2011.

MACHADO, A. T. M. A construção de um programa de revitalização na bacia do Rio São Francisco. Estudos Avançados, São Paulo, v. 22, n.63, 2008 .

MACHADO, G. Transformações na Paisagem da Bacia do Rio Marrecas (sw/pr) e Perspectivas de Desenvolvimento Territorial. Universidade Estadual Paulista, Faculdade de Ciências e Tecnologia, Presidente Prudente, 2009, 286p. Tese (Doutorado em Geografia). UNESP - Presidente Prudente, 2009.

MACÊDO, J. A. B., Métodos Laboratoriais de Análises Físicas, Químicas e Microbiológicas, Editora CRQ, 601 p, 2005.

MACEDO, M. F. Avaliação do sistema de monitoramento de recursos hídricos e da viabilidade técnica, legal e econômica da aplicação da Resolução CONAMA 357/2005 para a Sub-Bacia do Ribeirão das Cruzes (Araraquara-SP). Dissertação de Mestrado. UNIARA. Araraquara/SP. 2007. 
MACIEL, T. de. S.; MACEDO, M. F. de. Análise da Influência do Ambiente Urbano na Qualidade das Águas do Ribeirão das Cruzes no Município de Araraquara- SP. Revista Unilins, São Paulo, 2007.

MAGALHÃES, D.P.; FERRÃO FILHO, A.S. A Ecotoxicologia no biomonitoramento de ecossistemas aquáticos. Oecologia Brasiliensis, v.12, n.3, p. 355-381, 2008.

MONDARDO, M.L. Os períodos das imigrações. Territórios e identidades em Francisco Beltrão/PR. dourados:2009. Dissertação (Mestrado em Geografia) Universidade Federal Da Grande Dourados. Dourados, 2009.

NERES, A. O.; LIMA, L. A. de.; CARDOZO, C. L.; ALVES, L. F.; MENEZES, J. M. Utilização de Sistemas de Informação Geográfica na caracterização hidrogeoquímica de aquíferos costeiros - Estudo de caso: Distrito de Tamoios, Cabo Frio (RJ). XV Simpósio Brasileiro de Sensoriamento Remoto - SBSR, Curitiba, PR, 2011.

SANTOS, G. V.; DIAS, H. C. T.; SILVA, A. P de S.; MACEDO, M. de N. C de. Análise Hidrológica e Socioambiental da Bacia Hidrográfica do Córrego Romão dos Reis, Viçosa-MG. Revista Árvore, Viçosa-MG, v.31, 2007.

SHIBATA, T.; SOLO-GABRIELE, H. M.; F LEMING L.E.; ELMIR. S. Monitoring marine recreational water quality using multiple microbial indicators in an urban tropical environment. Water Research, v.38, p.3119-3131, 2004.

STATSOFT INC. Statistica data analysis system version 7.0. 1. ed. Tulsa, Statsoft Inc. 2004.

STROHSCHOEN, A. A. G.; PÉRICO, E.; LIMA, B. F. B. de.; REMPEL, C. Estudo Preliminar da Qualidade da Água dos Rios Forqueta e Forquetinha, Rio rande do Sul. Revista Brasileira de Biociências, Porto Alegre-RS, 2009.

VASCO, A. N.; MELlO JÚNIOR, A.V.; SANTOS, A. C. A. da S.; RIBEIRO, D. O.; TAVARES, E. D.; NOGUEIRA, L.C. Qualidade da Água que Entra no Estuário do Rio Vaza Barris Pelo Principal Fluxo de Contribuição de Água Doce. Scientia Plena, v.6, 2010.

VASCONCELLOS, F. C. S.; IGANCI, J. R. V.; RIBEIRO G. A. Qualidade microbiológica da água do Rio São Lourenço, São Lourenço do Sul, Rio Grande do Sul. Arquivos do Instituto Biológico, São Paulo, v.73, n.2, p.177-181, abr./jun., 2006. 